\title{
Differential endocannabinoid regulation of extinction in appetitive and aversive Barnes maze tasks
}

\author{
John P. Harloe, Andrew J. Thorpe, and Aron H. Lichtman ${ }^{1}$ \\ Department of Pharmacology and Toxicology, Medical College of Virginia Campus, Virginia Commonwealth University, \\ Richmond, Virginia 23284, USA
}

\begin{abstract}
$\mathrm{CB}_{1}$ receptor-compromised animals show profound deficits in extinguishing learned behavior from aversive conditioning tasks, but display normal extinction learning in appetitive operant tasks. However, it is difficult to discern whether the differential involvement of the endogenous cannabinoid system on extinction results from the hedonics or the required responses associated with the disparate tasks. Here, we report that the $C_{1}$ receptor antagonist rimonabant disrupts extinction learning in an aversive, but not in an appetitive, Barnes maze conditioning task. Accordingly, these results provide compelling support for the hypothesis that the endogenous cannabinoid system plays a necessary role in the extinction of aversively motivated behaviors but is expendable for appetitively motivated behaviors.
\end{abstract}

The centrally occurring endogenous cannabinoid (endocannabinoid) system is comprised of the G-protein-coupled $\mathrm{CB}_{1}$ receptor, its endogenous ligands, 2-arachyldonyl glycerol (2-AG) and anandamide (AEA), and enzymes responsible for the biosynthesis and degradation of these ligands (Ahn et al. 2008). A growing body of literature has implicated the endocannabinoid system in extinction learning in which learned behavior becomes suppressed when reinforcement is withheld. Disruption of $\mathrm{CB}_{1}$ receptor signaling, through either genetic deletion of the receptor or administration of a receptor antagonist, impairs extinction learning in a variety of aversively motivated tasks, including conditioned freezing, passive avoidance, and Morris water maze paradigms (Marsicano et al. 2002; Suzuki et al. 2004; Varvel et al. 2005; Niyuhire et al. 2007). A common aspect of these tasks is that each uses aversive unconditioned stimuli. In contrast, disruption of $\mathrm{CB}_{1}$ receptor signaling failed to affect extinction learning in operant conditioning tasks that use palatable food as the reinforcer (Holter et al. 2005; Niyuhire et al. 2007; Ward et al. 2007). To account for the differential consequences of $\mathrm{CB}_{1}$ deletion on extinction learning in operant and other behavioral paradigms, Holter et al. (2005) hypothesized that the endocannabinoid system plays an important role in the extinction of aversively motivated learned behavior but is dispensable for the extinction of appetitively motivated behavior. A challenge in interpreting the differential role that the endogenous cannabinoid system plays on extinction learning is the difficulty in comparing the results of experiments across different behavioral paradigms. In particular, the studies examining appetitively motivated behavior employed operant procedures, which have qualitatively different behavioral demands than conditioned fear paradigms or the Morris water maze. Thus, it may be that extinction of operant behavior, rather than the hedonic value of the reinforcer, is refractory to $\mathrm{CB}_{1}$ receptor disruption.

To focus on the qualitative nature of the reinforcer, we modified the Barnes maze task in the present study to evaluate appetitively and aversively motivated conditioning procedures on extinction, but required the same motor responses (i.e., searching for and entering the goal box). The Barnes maze (Hamilton-Kinder) consisted of a round board (122 cm diameter) fabricated from PVC with 40 holes $(2.54 \mathrm{~cm}$ diameter) surrounding

'Corresponding author.

E-mail alichtma@vcu.edu; fax (804) 828-2117.

Article is online at http://www.learnmem.org/cgi/doi/10.1101//m.1113008. the perimeter of the maze. The maze was divided into six zones, each containing a possible location for the goal box $(19.5$ $\mathrm{cm} \times 5.5 \mathrm{~cm}$ ). Contextual cues (i.e., various dark shapes) were attached to white curtains that were hung from a square 152 $\mathrm{cm} \times 152 \mathrm{~cm}$ aluminum frame enclosure that encircled the maze. A circular starting tube $(7.62 \mathrm{~cm}$ internal diameter) was placed in the center of the maze to ensure that all subjects began each trial from the same location. The tube was attached to a cord and pulley system, which the investigator raised from outside the enclosure. The trial began $3 \mathrm{sec}$ after the subject was placed in the starting tube. A digital camera (Panasonic BP-330), connected to a nearby computer running AnyMaze software (Stoelting), allowed the observer to watch and record without disturbing the subject. Both the maze and goal box were wiped with an ammonia-based cleaner (Whistle; JohnsonDiversey, Inc.) after each trial. Water was used as the reinforcer in the appetitive task because disruption of $\mathrm{CB}_{1}$ receptor signaling generally reduces operant responding for and the intake of palatable food (Holter et al. 2005; Ward et al. 2007), but does not affect water consumption (Arnone et al. 1997). To the best of our knowledge, there are no published reports employing access to drinking water to motivate learning in the Barnes maze task. Thus, in an initial study, we compared Barnes maze acquisition under appetitively reinforcing conditions in which mice that were water-deprived for 22 $\mathrm{h}$ gained access to drinking water when entering the goal box to a standard aversive procedure in which the mice entered the goal box to escape bright lights (i.e., two 500-watt halogen bulbs producing 3150 lux) and air turbulence from two 60 -cm-wide fans (Holmes). To evaluate Barnes maze performance under conditions common to both the aversive and appetitive procedures, a third group of subjects was assessed under ambient laboratory conditions that did not employ bright lights, air turbulence, water access, or water deprivation. In the appetitive and ambient procedures, the maze was illuminated with fluorescent lighting that produced 410 lux. Thus, the behavioral demands of the task (i.e., locating and entering the hidden compartment) were kept constant for all three conditioning groups, and only the nature of the reinforcer was experimentally manipulated.

As shown in Figure 1A, male C57BL/6J mice (Jackson Laboratory, Bar Harbor, ME) that were singly housed readily learned to enter the goal box under all three conditioning procedures $\left(F_{(9,396)}=52, P<0.0001\right)$. However, mice in the aversive and appetitive groups showed accelerated acquisition rates compared to 
A.

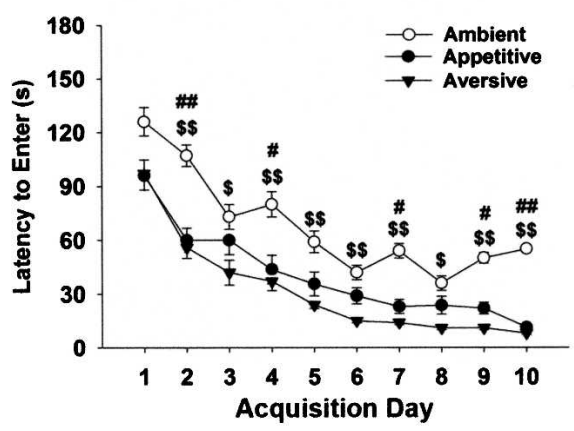

B.

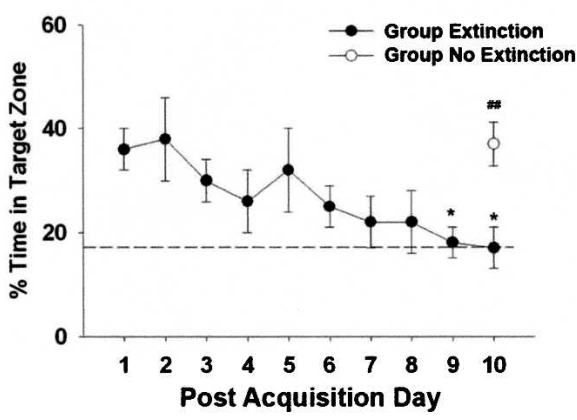

c.

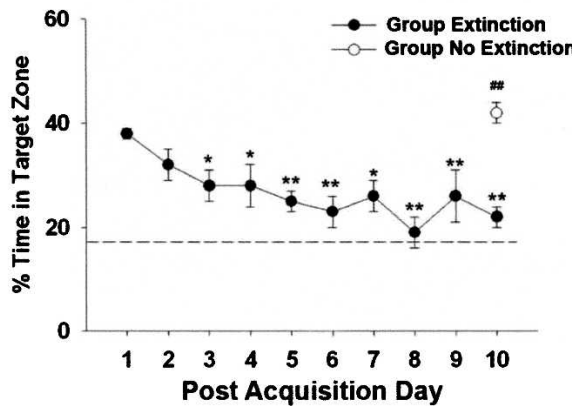

Figure 1. Learning in the Barnes maze under ambient, aversive, and appetitive conditioning procedures. (A) Mice learned to enter a hidden goal box in the Barnes maze under all conditions, though latencies were more significantly elevated under ambient conditions than in either appetitive or aversive procedures. (\#) $P<0.05$; (\#\#) $P<0.01$ vs. the appetitive condition. (\$) $P<0.05 ;(\$) P<0.01$ vs. aversive condition. The data for each session represent the average of four daily 3-min trials \pm SEM. $N=8-20$ mice/group. Percentage of time spent in the target zone (i.e., the zone previously containing the escape box) during extinction of an aversive (B) and appetitive (C) Barnes maze tasks. Following the $10 \mathrm{~d}$ of acquisition training, subjects in Group Extinction were given daily 3-min exposures to Barnes maze, but the goal box was removed. Group No Extinction received a single 3-min trial in the Barnes maze without the goal box that coincided with extinction day 10 . The dotted line from the $16.7 \%$ point of the ordinate spanning the width of the abscissa indicates chance performance. $\left(^{*}\right) P<0.05 ;\left(^{* *}\right) P<0.01$ vs. Group Extinction. All data are represented as mean \pm SEM, $N=7-10$ mice/group.

the ambient group $\left(F_{(2,396)}=15, P<0.0001\right)$, suggesting that access to water or escape from bright lights and air turbulence provides additional motivation to enter the goal box. Subjects in the aversive and appetitive conditioning groups spent similar percentages of time in the target zone during the first probe trial in which the escape box was removed from the maze, suggesting that both conditioning groups recalled the location of the escape box (Fig. 1B,C). Subjects trained in either the aversive $\left(F_{(9,54)}=2.8, P<0.01\right.$; Fig. $\left.1 \mathrm{~B}\right)$ or appetitive $\left(F_{(9,81)}=4.1\right.$, $P<0.001$; Fig. 1C) conditioning paradigm underwent extinction, as indicated by significant decreases in the percentage of time spent in the target zone across the 10 probe sessions. In order to distinguish between extinction and forgetting, two additional groups of mice (Group No Extinction) were given $10 \mathrm{~d}$ of acquisition training in either the aversive or appetitive conditioning procedure. However, each of these groups received only a single 3-min probe trial that coincided with probe trial day 10 for the groups that underwent extinction training. Group No Extinction in the aversive conditioning $\left(t_{(13)}=3.0, P<0.01\right)$ and appetitive conditioning $\left(t_{(15)}=4.9, P<0.001\right)$ procedures spent significantly more time in the target zone than the respective extinction groups on probe trial day 10. No differences were observed when comparing the percentage of time spent in the target zone between the single probe trial of Group No Extinction and the first extinction trial of Group Extinction in the aversive $(P=0.93)$
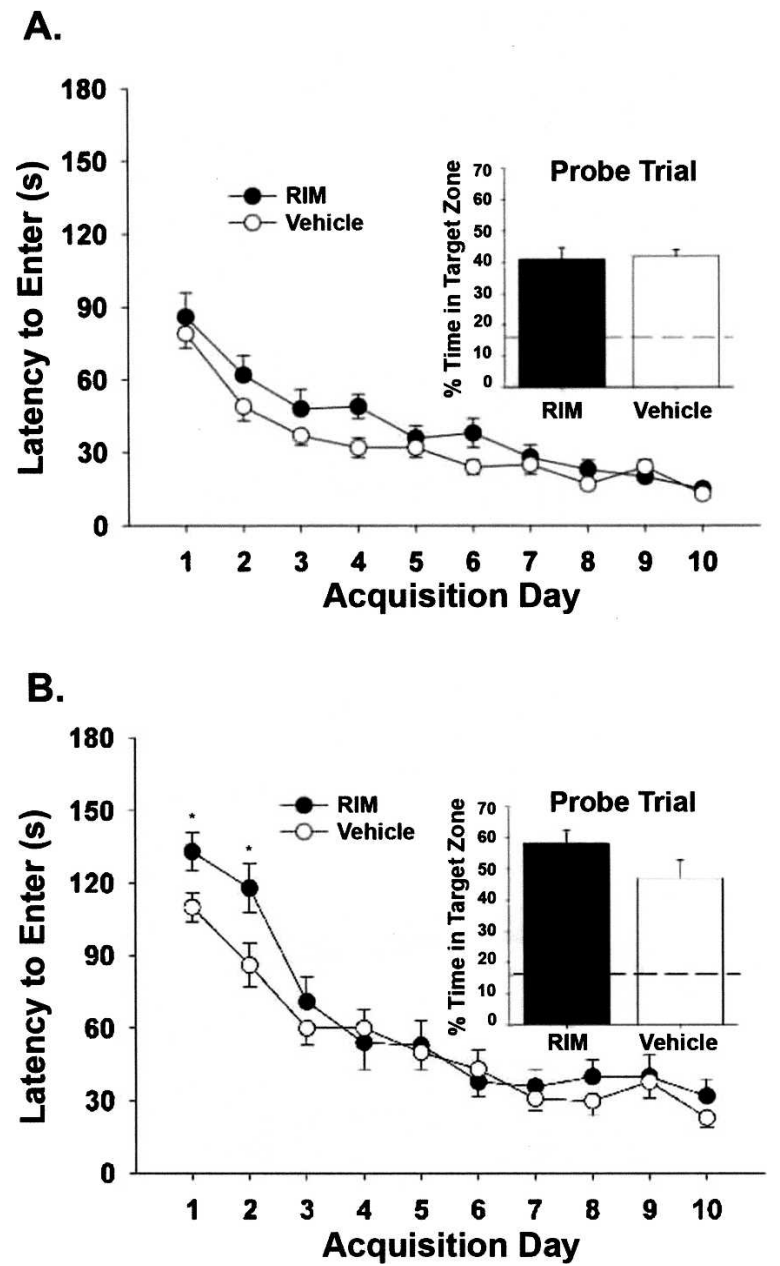

Figure 2. Rimonabant administration ( $3 \mathrm{mg} / \mathrm{kg}$ ) does not affect acquisition in either the aversive conditioning $(A)$ or the appetitive conditioning (B) Barnes maze task. The data for each acquisition session are represented as the average of four daily trials \pm SEM. (Insets) The day after the final acquisition session, subjects were given a $3-\mathrm{min}$ probe trial to evaluate memory. No treatment differences were observed for the percentage of time spent in the target zone. The dotted line from the $16.7 \%$ point of the ordinate spanning the width of the abscissa indicates chance performance. $\left.{ }^{*}\right) P<0.05$ vs. vehicle group. All data are represented as mean \pm SEM, $N=17-20$ mice/group. 
A.

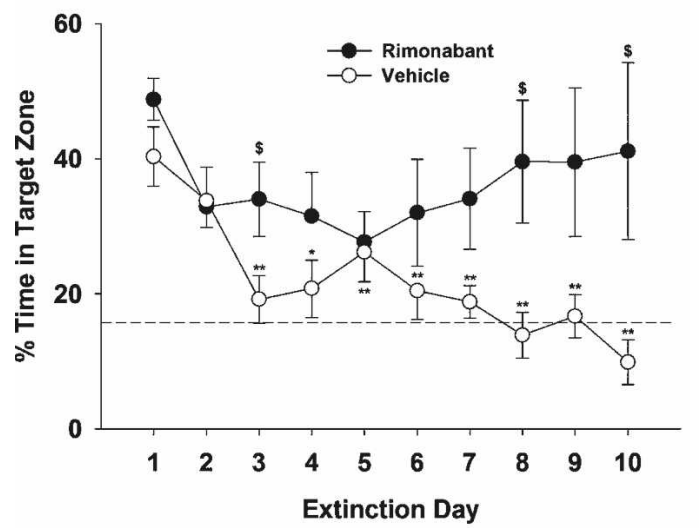

C.

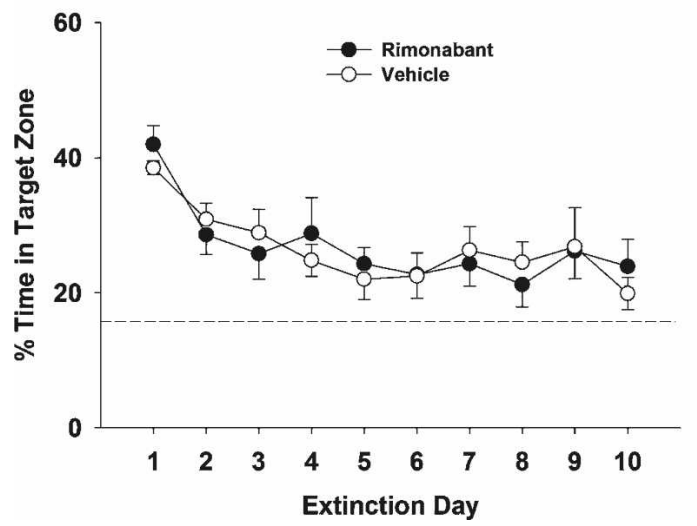

B.

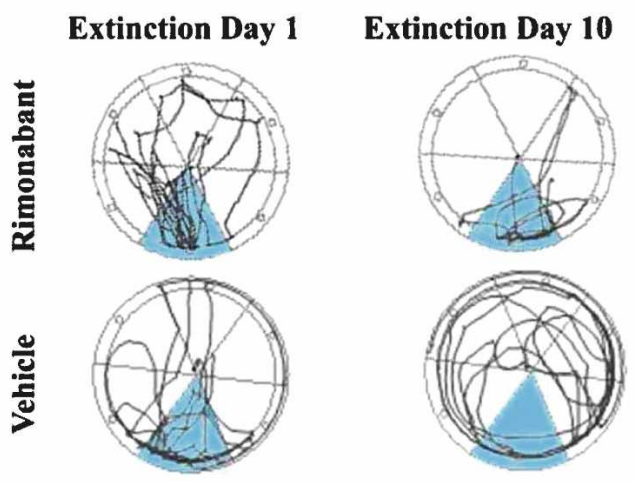

D.

Extinction Day 1

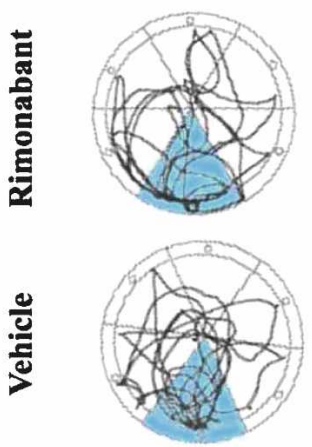

Extinction Day 10

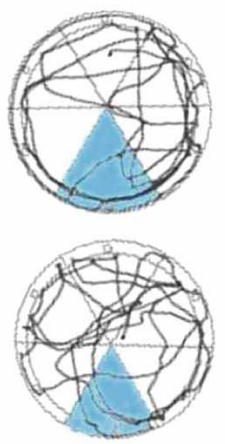

Figure 3. Rimonabant $(3 \mathrm{mg} / \mathrm{kg}$ ) differentially impairs extinction learning in appetitive and aversive Barnes maze conditioning tasks. (A) Aversive conditioning paradigm. Vehicle-treated mice underwent extinction across the daily probe trials; however, the rimonabant-treated mice exhibited impaired extinction learning. $\left.{ }^{*}\right) P<0.05 ;\left(^{* *}\right) P<0.01$ vs. extinction day $1 .(\$) P<0.05$ vs. the vehicle group. (B) Track plots of representative vehicleand rimonabant-treated mice on extinction days 1 and 10 in the aversive conditioning task. (C) Rimonabant-treated mice in the appetitive conditioning task underwent a similar rate of extinction as the vehicle-treated mice. $(D)$ Track plots of representative vehicle- and rimonabant-treated mice on extinction days 1 and 10 in the appetitive conditioning task. The dotted line from the $16.7 \%$ point of the ordinate spanning to the width of the abscissa indicates chance performance $(A, C)$. The target zone (i.e., the area that previously contained the goal box) for each trace $(B, D)$ is highlighted. All data are represented as mean \pm SEM, $N=7-9$ mice/group.

and appetitive $(P=0.26)$ conditioning tasks. Thus, under both aversive and appetitive conditioning procedures, subjects still recall the location of the escape box $10 \mathrm{~d}$ after training. However, daily 3-min exposures to the Barnes maze, with no goal box present, were sufficient to elicit extinction under both conditioning regimens. Collectively, these results support the utilization of this model as a viable method of assessing spatial memory in a paradigm in which the nature of reinforcement is varied, but the behavioral demands of the task remain constant.

Having established appetitively motivated and aversively motivated Barnes maze conditioning tasks, we next evaluated whether the $\mathrm{CB}_{1}$ receptor antagonist rimonabant $(3 \mathrm{mg} / \mathrm{kg}$, i.p.; National Institute on Drug Abuse) injected $30 \mathrm{~min}$ before each acquisition session would enhance learning. Indeed, previous research has demonstrated that rimonabant can enhance memory in radial arm maze and operant tasks (Lichtman 2000; Wolff and Leander 2003; Shiflett et al. 2004; Deadwyler et al. 2007; Wise et al. 2007), though not in all cases (Mansbach et al. 1996; Brodkin and Moerschbaecher 1997; Mallet and Beninger 1998; Hampson and Deadwyler 2000; Varvel et al. 2005). No effects of drug were found on latency to enter the goal box in the aversive conditioning task (Fig. 2A; $P=0.09$ ). Following acquisition, the goal box was removed and a 3-min probe trial was used to evaluate memory of the task. Both groups spent a similar percentage of time in the zone formerly associated with escape (i.e., target zone), but did not differ from one another (Fig. 2A, inset; $P=0.79$ ). In contrast, a significant interaction between drug treatment and conditioning day was found for escape latency in the mice given appetitive conditioning (Fig. $2 \mathrm{~B} ; F_{(9,288)}=2.0$, $P<0.05)$, with rimonabant-treated mice having significantly longer escape latencies than vehicle-treated mice on acquisition days 1 and 2, only. This difference in escape latency during the first few days was likely due to rimonabant-induced hypomotility in which the rimonabant-treated mice spent more time immobile than the vehicle-treated mice on the first three acquisition days $\left(F_{(9,288)}=3.1, P<0.01\right.$; data not shown). Nonetheless, both groups showed virtually identical acquisition rates, with equivalent goal box entry rates on days $2-8$. As in the case of the aversive conditioning procedure, both groups spent more time in the target zone than any of the other zones, but did not differ from one another (Fig. 2B, inset; $P=0.12$ ). The findings that rimonabant did not affect acquisition in either appetitive or aversive conditioning Barnes maze tasks are in agreement with previous results from the Morris water maze (Varvel et al. 2005), passive avoidance (Mazzola et al. 2003; Niyuhire et al. 2007), and conditioned fear (Marsicano et al. 2002; Suzuki et al. 2004; Varvel et al. 2005; Niyuhire et al. 2007) paradigms.

In the final experiment, mice were given $10 \mathrm{~d}$ of acquisition 
training using either aversive or appetitive Barnes maze conditioning procedures. Following the acquisition phase, extinction training was given in which the goal box was removed, and subjects were given daily injections of vehicle or rimonabant $(3 \mathrm{mg} /$ $\mathrm{kg}) 30 \mathrm{~min}$ before each of the daily 3 -min probe trials. In the aversive conditioning paradigm, daily administration of rimonabant led to extinction deficits, as indicated by a significant interaction between treatment and day in the percentage of time spent in the target zone (Fig. $3 \mathrm{~A} ; F_{(9,126)}=2.2, P<0.05$ ). The vehicle-treated mice showed a reduction in the percentage of time spent in the target zone across day $\left(F_{(9,63)}=8.2, P<0.0001\right)$, with a significant decrease in the time spent in the target zone by day 3. In contrast, rimonabant-treated mice continued to perseverate in the target zone across all 10 extinction sessions, with no significant reductions $(P=0.45)$. As can be inferred by the large standard error bars associated with the rimonabant-treated group, a subset of these mice spent chance levels or less of their time in the target zone, suggesting that the endocannabinoid system does not ubiquitously modulate extinction of aversive memories in all mice. Representative traces of vehicle- and rimonabant-treated mice on days 1 and 10 of extinction are depicted in Figure 3B. Both groups displayed a substantial bias for the target zone on the first extinction probe trial. Whereas the vehicle-treated mice no longer showed a bias for the target zone on extinction day 10, the rimonabant-treated animals continued to display a heavy bias for the target zone.

On the other hand, rimonabant failed to alter extinction learning in the appetitive Barnes maze conditioning paradigm. Both rimonabant- and vehicle-treated subjects exhibited a gradual reduction in the percentage of time spent in the target zone (Fig. 3C; $F_{(9,126)}=9.1, P<0.0001$ ). However, neither a main effect of drug $(P=0.94)$ nor an interaction between drug and extinction day $(P=0.72)$ was observed. As shown by the representative traces in Figure 3D, both groups showed a strong bias toward the target zone on the first extinction probe trial but $10 \mathrm{~d}$ of extinction training reduced the preference for the target zone, regardless of drug treatment.

In summary, we modified the Barnes maze task to examine the effects of the $\mathrm{CB}_{1}$ receptor antagonist rimonabant on extinction learning using either aversive or appetitive Barnes maze tasks. The present study represents the first case in which the same behavioral demands were required, but only the reinforcement was varied. Here, we report that rimonabant treatment disrupted extinction learning in the Barnes maze under aversive, but not under appetitive, conditions. This pattern of findings is consistent with the notion that the endocannabinoid system might become activated specifically in highly aversive situations, as has been previously demonstrated (Haller et al. 2004). Indeed, several other studies have demonstrated that $C_{1}$ receptorcompromised rodents exhibit impaired extinction learning of aversive, but not of appetitive, memories (Lutz 2007). Similarly, psychiatric patients diagnosed with post-traumatic stress disorder (PTSD) display deficits in extinguishing certain maladaptive behaviors associated with the trauma that they had suffered (Rothbaum and Davis 2003). Thus, further research is needed to examine whether the endocannabinoid system not only plays a role in PTSD, but also represents a therapeutic target to treat symptoms related to this condition. In conclusion, our findings provide compelling support for the hypothesis that the endocannabinoid system modulates the extinction of behaviors that are associated with aversive memories (Marsicano et al. 2002; Suzuki et al. 2004; Varvel et al. 2005), leaving extinction of learned behaviors from appetitively reinforced tasks intact (Holter et al. 2005; Niyuhire et al. 2007; Ward et al. 2007).

\section{Acknowledgment}

This work was supported by NIDA grants DA015683 and T23DA07027.

\section{References}

Ahn, K., McKinney, M.K., and Cravatt, B.F. 2008. Enzymatic pathways that regulate endocannabinoid signaling in the nervous system. Chem. Rev. 108: 1687-1707.

Arnone, M., Maruani, J., Chaperon, F., Thiebot, M.H., Poncelet, M., Soubrie, P., and Le Fur, G. 1997. Selective inhibition of sucrose and ethanol intake by SR 141716, an antagonist of central cannabinoid $\left(\mathrm{CB}_{1}\right)$ receptors. Psychopharmacology 132: 104-106.

Brodkin, J. and Moerschbaecher, J.M. 1997. SR141716A antagonizes the disruptive effects of cannabinoid ligands on learning in rats. $J$. Pharmacol. Exp. Ther. 282: 1526-1532.

Deadwyler, S.A., Goonawardena, A.V., and Hampson, R.E. 2007. Short-term memory is modulated by the spontaneous release of endocannabinoids: Evidence from hippocampal population codes. Behav. Pharmacol. 18: 571-580.

Haller, J., Varga, B., Ledent, C., Barna, I., and Freund, T.F. 2004. Context-dependent effects of $\mathrm{CB}_{1}$ cannabinoid gene disruption on anxiety-like and social behaviour in mice. Eur. J. Neurosci. 19: 1906-1912.

Hampson, R.E. and Deadwyler, S.A. 2000. Cannabinoids reveal the necessity of hippocampal neural encoding for short-term memory in rats. J. Neurosci. 20: $8932-8942$.

Holter, S.M., Kallnik, M., Wurst, W., Marsicano, G., Lutz, B., and Wotjak, C.T. 2005. Cannabinoid $\mathrm{CB}_{1}$ receptor is dispensable for memory extinction in an appetitively motivated learning task. Eur. J. Pharmacol. 510: 69-74.

Lichtman, A.H. 2000. SR 141716A enhances spatial memory as assessed in a radial-arm maze task in rats. Eur. J. Pharmacol. 404: 175-179.

Lutz, B. 2007. The endocannabinoid system and extinction learning. Mol. Neurobiol. 36: 92-101.

Mallet, P.E. and Beninger, R.J. 1998. The cannabinoid CB1 receptor antagonist SR141716A attenuates the memory impairment produced by $\Delta$-9-tetrahydrocannabinol or anandamide. Psychopharmacology 140: $11-19$.

Mansbach, R.S., Rovetti, C.C., Winston, E.N., and Lowe III, J.A. 1996. Effects of the cannabinoid $\mathrm{CB}_{1}$ receptor antagonist SR141716A on the behavior of pigeons and rats. Psychopharmacology 124: 315-322.

Marsicano, G., Wotjak, C.T., Azad, S.C., Bisogno, T., Rammes, G., Cascio, M.G., Hermann, H., Tang, J., Hofmann, C., Zieglgansberger, W., et al. 2002. The endogenous cannabinoid system controls extinction of aversive memories. Nature 418: 530-534.

Mazzola, C., Micale, V., and Drago, F. 2003. Amnesia induced by $\beta$-amyloid fragments is counteracted by cannabinoid $\mathrm{CB}_{1}$ receptor blockade. Eur. J. Pharmacol. 477: 219-225.

Niyuhire, F., Varvel, S.A., Thorpe, A.J., Stokes, R.J., Wiley, J.L., and Lichtman, A.H. 2007. The disruptive effects of the $\mathrm{CB}_{1}$ receptor antagonist rimonabant on extinction learning in mice are task-specific. Psychopharmacology 191: 223-231.

Rothbaum, B.O. and Davis, M. 2003. Applying learning principles to the treatment of post-trauma reactions. Ann. N. Y. Acad. Sci. 1008: $112-121$

Shiflett, M.W., Rankin, A.Z., Tomaszycki, M.L., and DeVoogd, T.J. 2004. Cannabinoid inhibition improves memory in food-storing birds, but with a cost. Proc. Biol. Sci. 271: 2043-2048.

Suzuki, A., Josselyn, S.A., Frankland, P.W., Masushige, S., Silva, A.J., and Kida, S. 2004. Memory reconsolidation and extinction have distinct temporal and biochemical signatures. J. Neurosci. 24: 4787-4795.

Varvel, S.A., Anum, E.A., and Lichtman, A.H. 2005. Disruption of $\mathrm{CB}_{1}$ receptor signaling impairs extinction of spatial memory in mice. Psychopharmacology 179: 863-872.

Ward, S.J., Walker, E.A., and Dykstra, L.A. 2007. Effect of cannabinoid $\mathrm{CB}_{1}$ receptor antagonist SR141716A and $\mathrm{CB}_{1}$ receptor knockout on cue-induced reinstatement of Ensure and corn-oil seeking in mice. Neuropsychopharmacology 32: 2592-2600.

Wise, L.E., Iredale, P.A., Stokes, R.J., and Lichtman, A.H. 2007. Combination of rimonabant and donepezil prolongs spatial memory duration. Neuropsychopharmacology 32: 1805-1812.

Wolff, M.C. and Leander, J.D. 2003. SR141716A, a cannabinoid CB $_{1}$ receptor antagonist, improves memory in a delayed radial maze task. Eur. J. Pharmacol. 477: 213-217.

Received June 18, 2008; accepted in revised form August 24, 2008. 


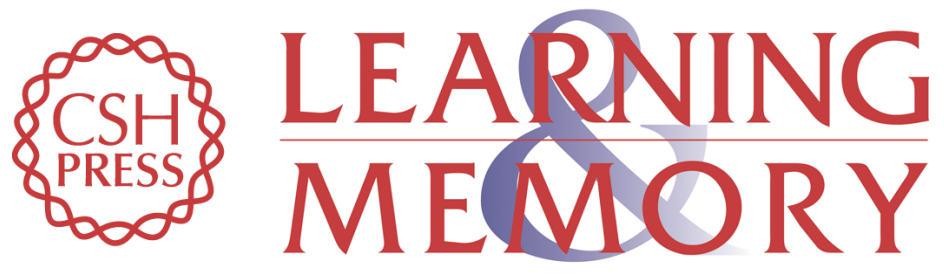

\section{Differential endocannabinoid regulation of extinction in appetitive and aversive Barnes maze tasks}

John P. Harloe, Andrew J. Thorpe and Aron H. Lichtman

Learn. Mem. 2008, 15:

Access the most recent version at doi:10.1101//m.1113008

References This article cites 21 articles, 3 of which can be accessed free at:

http://learnmem.cshlp.org/content/15/11/806.full.html\#ref-list-1

License

Email Alerting Receive free email alerts when new articles cite this article - sign up in the box at the Service top right corner of the article or click here. 